\title{
Serum Amyloid A Type 1 Gene Polymorphism in Egyptian Children with Familial Mediterranean Fever
}

\author{
Manal Wilson ${ }^{a}$ Amany A. Abou-Elallad ${ }^{d}$ Mervat Talaat Zakariab \\ Huda Marzouk $^{b}$ Hala Lotfy Fayed $^{c}$ Mariam Onsy F. Hanna $^{a}$ \\ Departments of a Clinical Pathology, ${ }^{b}$ Pediatrics and ${ }^{\mathrm{c}}$ Rheumatology and Rehabilitation, Cairo University, and \\ ${ }^{\mathrm{d}}$ Technology of Medical Laboratory Department, Faculty of Applied Medical Sciences, Misr University for Science \\ and Technology, Cairo, Egypt
}

\section{Key Words}

Familial Mediterranean fever $\cdot$ Gene polymorphism $\cdot$ Serum amyloid A type 1

\begin{abstract}
Background: Since spontaneous inflammation is an important contributor to familial Mediterranean fever (FMF), genetic variants mediating inflammation are of interest. We investigated gene variants in the acute-phase serum amyloid A type 1 (SAA1), a sensitive marker of inflammatory activity, and their association with susceptibility and severity of FMF. Methods: The genotypes of 2 single-nucleotide polymorphisms within exon 3 of SAA1 (2995C/T and 3010C/T) were determined in 105 Egyptian children with FMF and in 125 controls by polymerase chain reaction-restriction fragment length polymorphism. Genotyping of the causative MEFV mutations was performed by reverse hybridization. Results: The M694I mutation was the most frequent allele (42.8\%), followed by V726A (18.6\%), M680I (17.1\%), E148Q (11.9\%) and M694V (9.0\%). The frequency of the SAA1 a, $\beta$ and $\gamma$ alleles was not significantly different between FMF patients and controls. The genotype frequency of $S A A 1 \mathrm{a} / \mathrm{a}$ was higher in patients than in healthy subjects ( 21.0 vs. $14.4 \%)$ although it did not reach statistical significance. The clinical manifestations including age at disease onset, number of FMF attacks, colchicine dose and severity score were not re-
\end{abstract}

\section{KARGER}

E-Mail karger@karger.com

www.karger.com/pat lated to genotypes of SAA1. However, M694V mutation and female gender were significantly associated with severity. Conclusion: The genetic polymorphism of SAA1 is not associated with susceptibility and severity of FMF in Egyptian children.

(c) 2016 S. Karger AG, Basel

\section{Introduction}

Familial Mediterranean fever (FMF) is a systemic autoinflammatory disease characterized by self-limited recurrent episodes of fever accompanied by peritoneal, pleural or synovial inflammation. FMF was originally described as a disease of autosomal recessive inheritance and early onset leading to significant morbidity. Missense mutations in the Mediterranean fever (MEFV) gene located on chromosome 16p13.3 have been observed to be causative of FMF [1]. Pyrin, the 781-amino acid protein product of the $M E F V$ gene, is expressed in the cytoplasm of monocytes, and the nucleus of dendritic cells, neutrophils, and synovial fibroblasts [2-6]. Five mutations, M694I, M680I, M694V and V726A in exon 10 and E148Q in exon 2, account for almost $90 \%$ of FMF mutations [7]. A major role of pyrin is the regulation of inflammation. FMF-associated mutations in pyrin activate interleukin (IL) $-1 \beta$ and induce the acute phase response.

Dr. Mariam Onsy F. Hanna

Department of Clinical Pathology, Cairo University

1 Al-Saray Street, Al-Manial

Cairo 11559 (Egypt)

E-Mail mariamhanna@cu.edu.eg 
Serum amyloid A (SAA) is markedly expressed in the acute inflammatory state during attacks as well as in between attacks of FMF [8]. In general, the plasma concentrations of SAA are biomarkers for host response to trauma, stress or infection. SAA synthesis, which occurs in the hepatocytes and epithelial cells, is induced by the inflammation-associated cytokines IL- 6 and IL- 1 and tumor necrosis factor- $\alpha$ (TNF- $\alpha$ ) [9]. Because cytokine regulation of SAA and cytokine inducing functions of SAA determine the magnitude and duration of the immune response, genetic variation in the acute-phase reactant may be related to the development of inflammatory diseases $[10,11]$ such as FMF.

The genes on chromosome 11 encode for the acutephase SAA type 1 (SAA1) protein, which is the predominant form of the $S A A$ gene family [12]. Three $S A A 1$ allelic variants have been defined on the basis of 2 singlenucleotide polymorphisms (SNPs) located in exon 3, i.e. $2995 \mathrm{C} / \mathrm{T}$ and $3010 \mathrm{C} / \mathrm{T}$, that correspond to the isoforms SAA1 a (2995T-3010C), SAA1 $\beta$ (2995C-3010T) and SAA1 $\gamma$ (2995C-3010C) or SAA1.1, SAA1.5 (originally considered as $S A A 1.2)$ and $S A A 1.3$, respectively [10,13$14]$. The 2 polymorphisms of the $S A A 1$ gene result in amino acid changes at positions 52 and 57, Val52-Ala57, Ala52-Val57 and Ala52-Ala57, respectively.

There is increasing evidence that genotypes at the $S A A 1$ locus are associated with raised susceptibility to AA amyloidosis $[15,16]$. For example, the genotype $\alpha / \alpha$ of the $S A A 1$ gene has been associated with a 7 -fold increase in the incidence of renal amyloidosis, [17] while a protective effect of the SAA1 $\beta$ and $\gamma$ alleles on the development of amyloidosis was suggested. However, the contribution of these genotypes to the occurrence of nonamyloid, inflammatory disease has not been fully elucidated, especially in Egyptian patients. FMF is presumed to be a monogenic disease, although the role of potential modifying genetic factors other than $M E F V$ in the development of FMF has been suggested [11].

In view of the recent genetic studies on FMF, SAA1 allelic variants may contribute to the susceptibility of FMF in addition to $M E F V$ mutations. Therefore, we attempted to determine the effect of gene polymorphisms on the susceptibility and severity of FMF in the pediatric Egyptian population.

\section{Methods}

Patients and Controls

Patients with FMF were diagnosed at the Rheumatology Department of the Pediatric Hospital of Cairo University. The medi- cal records of the children with FMF were evaluated retrospectively for gender, age at the onset of symptoms and time of diagnosis, clinical signs and symptoms and MEFV genotype. The study included 105 children with FMF diagnosed according to established FMF criteria [18] and genetically confirmed with $2 \mathrm{MEFV}$ gene mutations. Age- and gender-matched apparently healthy children $(\mathrm{n}=125)$, with no family history or clinical manifestations suggestive of FMF and negative for the $M E F V$ gene mutation, were assigned to the control group. Severity score was assessed according to Mor et al. [19] modified for children by Ozen et al. [20] and Pras et al. [8]. The study was approved by the ethical committee of Cairo University.

\section{MEFV Gene Mutation Analysis}

Molecular genetic mutation analysis of the $M E F V$ gene was performed for patients and controls using the reverse hybridization assay (FMF StripAssay; ViennaLab, Vienna, Austria). In brief, exons 2, 3, 5 and 10 were amplified in a single multiplex polymerase chain reaction (PCR). The amplification program was 35 cycles including $94^{\circ} \mathrm{C}$ for $15 \mathrm{~s}, 58^{\circ} \mathrm{C}$ for $45 \mathrm{~s}, 72^{\circ} \mathrm{C}$ for $45 \mathrm{~s}$ and a final extension at $72^{\circ} \mathrm{C}$ for $7 \mathrm{~min}$. Biotinylated PCR products were hybridized to allele-specific oligonucleotide probes and the 12 common mutations, E148Q in exon 2, P369S in exon 3, F479L in exon 5 and M680I (G/C) and M680I (G/A), I692del, M694V, M694I, K695R, V726A, A744S and R761H in exon 10 were determined. In individuals with symptoms of FMF, mutation analysis of the common $M E F V$ mutations identified double (homozygous or compound heterozygous) mutations, confirming the diagnosis.

\section{SAA1 Genotyping}

The genotyping of exon 3 of SAA1 SNP was performed using PCR-restriction fragment length polymorphism (RFLP) assay.

\section{DNA Extraction and Purification}

Total genomic DNA from FMF patients and healthy controls was extracted from EDTA-anticoagulated whole blood using DNA extraction and a purification kit according to the manufacturer's instructions (Thermo Scientific).

\section{PCR Amplification}

DNA was amplified by PCR using $5^{\prime}$-GCC AAT TAC ATC GGC TCA G-3' (sense) and 5' -TGG CCA AAG AAT CTC TGG AT-3' (antisense), primers spanning exon 3 of SAA1 [10]. PCR reactions were carried out in $2 \times$ Dream Taq Green PCR master mix (Thermo Scientific) containing DreamTaq ${ }^{\mathrm{TM}}$ DNA polymerase, $0.4 \mathrm{mM}$ of dATP, dCTP, dGTP and dTTP and $4 \mathrm{mM} \mathrm{MgCl} 2$ with $0.4 \mu \mathrm{M}$ of each primer. PCR amplification was performed as follows: initial denaturation at $94^{\circ} \mathrm{C}$ for $5 \mathrm{~min}$ followed by 35 cycles of denaturation at $94^{\circ} \mathrm{C}$ for $60 \mathrm{~s}$, annealing at $62^{\circ} \mathrm{C}$ for $60 \mathrm{~s}$ and extension at $72^{\circ} \mathrm{C}$ for $7 \mathrm{~min}[21]$.

\section{RFLP Assay}

The 530-bp PCR products were then digested by BanI and BclI (Fermentas, Germany) and DNA fragments were then separated by electrophoresis in $2.5 \%$ agarose gel stained with ethidium bromide. With the enzyme BanI, the amplified a allele was digested into 3 fragments (317, 188 and $25 \mathrm{bp}$ ), while the amplified $\beta$ and $\gamma$ alleles were digested into 4 fragments $(244,188,73$ and $25 \mathrm{bp})$. With $B c l$ I, the DNA amplified from the $\beta$ allele was digested into 2 fragments (438 and $92 \mathrm{bp}$ ), while that from the $\alpha$ and $\gamma$ alleles was not digested [13]. 
Table 1. Demographic and clinical features of 105 FMF patients

\begin{tabular}{lc}
\hline Males/females & $50 / 55$ \\
Age at disease onset, years & $5.4 \pm 3.7$ \\
Age at diagnosis, years & $7.2 \pm 4.0$ \\
Disease duration, years & $3.9 \pm 2.8$ \\
Number of attacks per month & $3.0 \pm 2.2$ \\
Duration of attacks, days & $1.7 \pm 1.4$ \\
Severity (mild/moderate/severe) & $24 / 36 / 45$ \\
Colchicine, mg/day & $1.0 \pm 0.4$ \\
Duration of colchicine treatment, years & $2.0 \pm 2.0$ \\
\hline
\end{tabular}

Values are presented as mean $\pm \mathrm{SD}$ or $\mathrm{n}$.

\section{Statistical Analysis}

Data were statistically described in terms of mean \pm standard deviation (SD), number of cases and percentages. For comparing categorical data, the $\chi^{2}$ test was performed. All statistical tests were 2 -sided. Linear regression analysis was used to study the contribution of independent variables to the severity of FMF. $\mathrm{p}<0.05$ was considered statistically significant. All statistical calculations were done using SPSS (Statistical Package for the Social Science; SPSS Inc., Chicago, Ill., USA) v20 for Microsoft Windows.

A power calculation by $\mathrm{G}^{*}$ power software was estimated where the $\chi^{2}$ test with an a value of 0.05 and effect size of 0.3 was employed. For total sample size i.e. 230 (105 FMF patients + 125 controls) a power equal to 0.96 for differences between the genotype frequencies in patients and controls and equal to 0.99 for allele differences was observed.

\section{Results}

\section{Clinical Features}

The clinical and demographic data of the FMF patients are summarized in table 1 . The ratio of males to females in patients with FMF was 0.9 (50:55). Consanguinity was recognized in 40/105 (38.1\%) patients. Both family cases and sporadic cases were observed; 20/105 (19.0\%) patients had a family history of FMF. The most common clinical features during the attacks were abdominal pain in $96.2 \%$, a high-grade fever $\left(\geq 38^{\circ} \mathrm{C}\right)$ in $91.4 \%$, arthralgia in $61.9 \%$ and chest pain in $56.2 \%$. Only $33.3 \%$ had myalgia and $21.0 \%$ had arthritis, while $6.7 \%$ of the patients had erysipelas-like lesions.

All the patients were treated with colchicine. The average dose was $1.0 \pm 0.4 \mathrm{mg} /$ day and $30.5 \%$ of patients received $<1.0 \mathrm{mg} /$ day. The disease was mild in $24(22.9 \%)$ patients, moderate in $36(34.3 \%)$ patients and severe in 45 patients $(42.9 \%)$, according to the modified scoring system of Mor et al. [19] and Ozen et al. [20]. The median
Table 2. Distribution of $M E F V$ mutations in FMF patients

\begin{tabular}{|c|c|c|c|}
\hline \multicolumn{2}{|l|}{ Homozygotes } & \multicolumn{2}{|l|}{ Compound heterozygotes } \\
\hline Mutation & n (\%) & Mutation & $\mathrm{n}(\%)$ \\
\hline M694I/M694I & $22(20.9)$ & M694I/E148Q & $16(15.2)$ \\
\hline M680I/M680I & $10(9.5)$ & M694I/V726A & $12(11.4)$ \\
\hline$V 726 A / V 726 A$ & $5(4.8)$ & M694I/M694V & $8(7.6)$ \\
\hline$M 694 \mathrm{~V} / \mathrm{M} 694 \mathrm{~V}$ & $2(1.9)$ & M694I/M680I & $6(5.7)$ \\
\hline \multirow[t]{14}{*}{$E 148 Q / E 148 Q$} & $1(0.9)$ & $M 680 I / V 726 A$ & $5(4.8)$ \\
\hline & & M680I/E148Q & $1(0.9)$ \\
\hline & & M680I/M694V & $1(0.9)$ \\
\hline & & M694V/E148Q & $3(2.8)$ \\
\hline & & $M 694 V / V 726 A$ & $2(1.9)$ \\
\hline & & M694V/A744S & $1(0.9)$ \\
\hline & & $V 726 A / P 369 S$ & $1(0.9)$ \\
\hline & & $V 726 A / E 148 Q$ & $1(0.9)$ \\
\hline & & V726A/1692del & $2(1.9)$ \\
\hline & & M694I/V726A/M680I & $2(1.9)$ \\
\hline & & M694I/V726A/E148Q & $1(0.9)$ \\
\hline & & M694I/V726A/1692del & $1(0.9)$ \\
\hline & & M680I/V726A/A744S & $1(0.9)$ \\
\hline & & $V 726 A / E 148 Q / 1692 \mathrm{del}$ & $1(0.9)$ \\
\hline Total & $40(38.1)$ & & 65 (61.9) \\
\hline
\end{tabular}

severity score was 6.0 (range $3-11$ ) according to Pras et al. [8].

\section{MEFV Gene Mutations}

Among the 105 patients, 40 (38.1\%) were homozygous and 65 (61.9\%) were compound heterozygous for $M E F V$ mutations. Table 2 shows the distribution of $M E F V$ mutations in the study. M694I and M694I/E148Q were the most frequent genotypes in the homozygote and heterozygote mutations, respectively. The M694I mutation was the most frequent allele $(42.8 \%)$, followed by $V 726 \mathrm{~A}$ (18.6\%), M680I (17.1\%), E148Q (11.9\%) and M694V (9.0\%).

\section{Association between SAA1 Gene Polymorphism and FMF}

The polymorphic sites of the $S A A 1$ gene were subjected to PCR-RFLP analysis. Table 3 shows the frequencies of individuals with various genotypes and alleles at the $S A A 1$ locus in pediatric FMF patients $(\mathrm{n}=105)$ and Egyptian control subjects $(n=125)$. The $S A A 1 \alpha, \beta$ and $\gamma$ alleles were encountered in both FMF patients and controls. The genotype frequency of $S A A 1$ a/a was higher in FMF patients than in healthy subjects (21.0 vs. $14.4 \%)$ although it did not reach statistical significance $(p=0.291)$. Conversely, 
Table 3. $S A A 1$ genotype and allele frequency in FMF patients and normal controls

\begin{tabular}{lccc}
\hline & $\begin{array}{l}\text { FMF patients } \\
(\mathrm{n}=105)\end{array}$ & $\begin{array}{l}\text { Controls } \\
(\mathrm{n}=125)\end{array}$ & \\
\hline SAA1 genotypes & & & \\
$\alpha / \alpha$ & $22(21.0)$ & $18(14.4)$ & $\chi^{2}=6.200$ \\
$\alpha / \beta$ & $37(35.2)$ & $43(34.4)$ & $\mathrm{p}=0.291$ \\
$\alpha / \gamma$ & $2(1.9)$ & $10(8.0)$ & \\
$\beta / \beta$ & $30(28.6)$ & $33(26.4)$ & \\
$\beta / \gamma$ & $7(6.7)$ & $12(9.6)$ & \\
$\gamma / \gamma$ & $7(6.7)$ & $9(7.2)$ & \\
$S A A 1$ alleles & & & \\
$\alpha$ & $83(39.5)$ & $89(35.6)$ & $\chi^{2}=2.623$ \\
$\beta$ & $104(49.5)$ & $121(48.4)$ & $\mathrm{p}=0.269$ \\
$\gamma$ & $23(11.0)$ & $40(16.0)$ & \\
\hline
\end{tabular}

Values are expressed as $\mathrm{n}(\%)$. The $\chi^{2}$ test was used to examine differences in allele and genotype frequencies between FMF patients and control subjects.

the allele frequency of $S A A 1 \gamma$ was lower in FMF patients than in healthy subjects ( 11.0 vs. $16.0 \%, \mathrm{p}=0.269)$.

\section{FMF Clinical Characteristics Related to Genotypes at}

the SAA1 Loci

The clinical manifestations, age at disease onset, number of FMF attacks, dose of colchicine required and severity score were not related to genotypes at the $S A A 1$ locus $(\mathrm{p}=0.884,0.838,0.778$ and 0.729 , respectively). Furthermore, patients bearing the SAA1 a/a genotype $(\mathrm{n}=22)$ did not differ from those bearing the $S A A 1 \alpha / \beta, \beta / \beta, \beta / \gamma$, $\alpha / \gamma$ and $\gamma / \gamma$ allelic combinations $(n=83)$ in terms of age at disease onset, number of attacks, dose of colchicine and severity score ( $\mathrm{p}=0.697,0.550,0.489$ and 0.419 , respectively). The severity score was not significantly different among those carrying the $S A A 1 \alpha / \alpha$ or $S A A 1 \beta / \beta$ or $S A A 1$ $\gamma / \gamma$ genotype compared with those bearing other $S A A 1$ allelic combinations ( $\mathrm{p}=0.419,0.970$ and 0.753 , respectively).

Based on the severity scoring system by Pras et al. [8], multivariate linear regression analyses showed that the $M E F V$ mutation $M 694 V$ [ $\beta=1.226$; 95\% confidence interval (CI) $0.290-2.162 ; \mathrm{p}=0.011$ ] as well as female gen$\operatorname{der}(\beta=0.648 ; 95 \%$ CI $0.044-1.252 ; \mathrm{p}=0.036)$ were significantly associated with increasing severity score. $S A A 1$ alleles $\alpha, \beta$ and $\gamma$ did not significantly affect severity $(\beta=$ 0.024 and $p=0.947, \beta=-0.180$ and $p=0.645$ and $\beta=$ -0.709 and $\mathrm{p}=0.166$, respectively).

\section{Discussion}

Variant alleles are present in $S A A 1$, which is the principal form of the $S A A$ gene family. SAA is a major acutephase protein, and emerging evidence has shown correlations between $S A A 1$ alleles and diseases including FMF [11]. However, our data indicate that $S A A 1$ gene polymorphism consisting of SNPs within exon 3 (i.e. 2995C/T and $3010 \mathrm{C} / \mathrm{T}$ ) that result in amino acid changes at positions 52 and 57, respectively, are not associated with susceptibility in Egyptian children with FMF. This is the first study reporting on the $S A A 1$ polymorphism in the Egyptian population.

It has recently been reported that in the Japanese population, in whom the SAA1.1 (a) allele occurs with a frequency of $34 \%$, possession of and homozygosity for this allele constitute a significant protective factor for FMF [11]. In contrast, it has been observed that, in healthy Turkish individuals and FMF patients without amyloidosis, the $S A A 1$ a allele did not significantly differ, at a frequency of 42.5 and $49.5 \%$, respectively, while among FMF patients with associated AA amyloidosis, there was a marked increased frequency of the SAA1 a allele (85.6\%) [22]. Similarly, no differences were detected in the distribution of genotype and allele frequencies of the 2 SNPs, 2995C/T and 3010C/T, between FMF patients without amyloidosis and the control group in a Greek population [23].

It remains unclear how the proteins encoded by the $S A A 1$ alleles function differently. It was proposed that the differences of the $S A A 1$ isoforms in their selectivity for SAA receptors may influence their roles in modulating inflammation [24]. For example, SAA1.1 (a) was more efficient than SAA1.3 $(\gamma)$ and SAA1.5 $(\beta)$ in the activation of the SAA receptor, formyl peptide receptor 2, that is present on phagocytes. In addition, the SAA1.3 $(\gamma)$ isoform was found to be potent in the induction of proinflammatory TNFa in macrophages whereas SAA1.5 ( $\beta$ ) stimulated anti-inflammatory IL-10 expression. Gouwy et al. [25] demonstrated that the SAA1 a isoform is able to chemoattract monocyte-derived immature dendritic cells. The chemotactic activity of SAA1 a was mediated by rapid chemokine stimulation, suggesting regulation of leukocyte recruitment to inflammatory sites.

In healthy individuals, SAA concentrations were found to be significantly higher in those possessing a $S A A$ $1.5(\beta)$ allele, and highest in homozygotes for the allele [26]. It was reported that the protein of the allelic variant of SAA $1.5(\beta)$ is cleared from the circulation more slow-
Wilson/Abou-Elalla/Zakaria/Marzouk/ Fayed/Hanna 
ly than other isoforms [27]. Furthermore, SAA1 induces the production of MMPs by monocytic cells [28] and MMPs degrade SAA1 preferentially in the site of the polymorphism at position 57. The $S A A 1.1(\alpha)$ isoform is more susceptible to cleavage by MMP-1 than SAA1.5 ( $\beta$ ), resulting in a higher production of the 1-57 fragments from SAA1.1 (a) [29].

The majority of FMF patients in this study had some combination of the M694I, V726A, M680I, E148Q and $M 694 \mathrm{~V}$ mutations. The M694I mutation was the most frequent allele (42.8\%), followed by V726A (18.6\%), M680I (17.1\%), E148Q (11.9\%) and M694V (9.0\%). The presence of M694I in exon 10 is important in FMF. Patients with the M694I mutation show an early onset, a high frequency and a short duration of attacks, in addition to high percentages of fever and serositis. However, their therapeutic response to colchicine is very good [30].

Our data suggest that the $S A A 1$ polymorphism does not influence the severity of FMF. Similarly, GershoniBaruch et al. [31] showed that disease severity was not associated with genotypes at the SAA1 locus, but was mainly influenced by $M E F V$ mutations. In this study, the $M 694 \mathrm{~V}$ allele significantly influenced severity $(\beta=1.226$; $95 \%$ CI 0.290-2.162; p = 0.011). Several studies have emphasized the observation that the severe phenotype of FMF is associated with the M694V mutation [17, 31]. Female gender also contributed to severity in the multivariate analysis $(\beta=0.648 ; 95 \%$ CI $0.044-1.252 ; \mathrm{p}=$ 0.036).
Type AA amyloidosis is a serious complication of FMF associated with persistent inflammation in inadequately treated disease. It is caused by the deposition of insoluble amyloid proteins in the extracellular spaces of different tissues $[32,33]$. The AA protein that forms the amyloid fibril is primarily derived from the degradation products of SAA1. Homozygosity for $S A A 1 \alpha$ and $S A A 1 \gamma$ in different populations is a significant risk factor for AA amyloidosis [34]. In FMF, homozygosity for the $M 694 \mathrm{~V}$ allele, arthritis attacks, male sex and the SAA1 a homozygous genotype were found to be independently associated with renal amyloidosis [31]. However, the development of amyloidosis differs in various ethnic populations. One consideration in this study is the association between the results of the amyloidogenic SAA1 genotype frequency in FMF patients and controls with the reported rare incidence of amyloidosis in Arabs (1.7\%) [35]. The prevalence of amyloidosis among patients attending renal clinics in North Africa varies between 4 and $9 \%$, and FMF is responsible for $11.6-30 \%$ of cases $[36,37]$.

In conclusion, $S A A 1$ allelic variants are not modifying genetic factors in the susceptibility or severity of FMF in the pediatric Egyptian population. However, the $M E F V$ mutation $M 694 \mathrm{~V}$ and female gender may be associated with more severe disease.

\section{Disclosure Statement}

The authors declare no conflicts of interest.

\section{References}

1 Chae JJ, Cho YH, Lee GS, Cheng J, Liu PP, Feigenbaum L, Katz SI, Kastner DL: Gain-offunction pyrin mutations induce NLRP3 protein-independent interleukin- $1 \beta$ activation and severe autoinflammation in mice. Immunity 2011;34:755-768.

2 Koc B, Oktenli C, Bulucu F, Karadurmus N, Sanisoglu SY, Gul D: The rate of pyrin mutations in critically ill patients with systemic inflammatory response syndrome and sepsis: a pilot study. J Rheumatol 2007;34:2070-2075.

3 Centola M, Aksentijevich I, Kastner DL: The hereditary periodic fever syndromes: molecular analysis of a new family of inflammatory diseases. Hum Mol Genet 1998;7:1581-1588.
4 Diaz A, Hu C, Kastner DL, Schaner P, Reginato AM, Richards N, Gumucido DL: Lipopolysaccharide-induced expression of multiple alternatively spliced $M E F V$ transcripts in human synovial fibroblasts: a prominent splice isoform lacks the C-terminal domain that is highly mutated in familial Mediterranean fever. Arthritis Rheum 2004;50:36793689 .

5 French FMF Consortium: a candidate gene for familial Mediterranean fever. Nat Genet 1997; 17:25-31.

6 The International FMF Consortium: Ancient missense mutations in a new member of the RoRet gene family are likely to cause familial Mediterranean fever. Cell 1997;90:797-807.

7 Touitou I: The spectrum of familial Mediterranean fever (FMF) mutations. Eur J Hum Genet 2001;9:473-483.
8 Pras E, Livneh A, Balow JE Jr, Pras E, Kastner DL, Pras M, Langevitz P: Clinical differences between North African and Iraqi Jews with familial Mediterranean fever. Am J Med Genet 1998;75:216-219.

9 Upragarin N, Landman WJM, Gaastra W, Gruys E: Extrahepatic production of acute phase serum amyloid A. Histol Histopathol 2005;20:1295-1307.

10 Baba S, Masago SA, Takahashi T, Kasama T, Sugimura H, Tsugane S, Tsutsui Y, Shirasawa $\mathrm{H}$ : A novel allelic variant of serum amyloid A, SAA 1 gamma: genomic evidence, evolution, frequency, and implication as a risk factor for reactive systemic A-amyloidosis. Hum Mol Genet 1995;4:1083-1087.
SAA1 Polymorphism in Familial Mediterranean Fever
Pathobiology 2016;83:295-300 DOI: $10.1159 / 000444933$ 
11 Migita K, Agematsu K, Masumoto J, Ida H, Honda S, Jiuchi Y, Izumi Y, Maeda Y, Uehara R, Nakamura Y, Koga T, Kawakami A, Nakashima M, Fujieda Y, Nonaka F, Eguchi K, Furukawa H, Nakamura T, Nakamura M, Yasunami M: The contribution of SAA1 polymorphisms to familial Mediterranean fever susceptibility in the Japanese population. PLoS One 2013;8:e55227.

12 Whitehead AS, de Beer MC, Steel DM, Rits M, Lelias JM, Lane WS, de Beer FC: Identification of novel members of the serum amyloid A protein superfamily as constitutive apolipoproteins of high density lipoprotein. J Biol Chem 1992;267:3862-3867.

13 Nakamura T, Baba S, Yamamura Y, Tsuruta T, Matsubara S, Tomoda K, Tsukano M: Combined treatment with cyclophosphamide and prednisolone is effective for secondary amyloidosis with $S A A 1 \gamma / \gamma$ genotype in a patient with rheumatoid arthritis. Mod Rheumatol 2000;10:160-164.

14 Yamada T: Genetic effects on serum concentrations of serum amyloid A protein. Clin Chem 2004;50:978-979.

15 Medlej-Hashim M, Delague V, Chouery E, Salem N, Rawashdeh M, Lefranc G, Loiselet J, Mégarbané A: Amyloidosis in familial Mediterranean fever patients: correlation with $M E F V$ genotype and SAA1 and MICA polymorphisms effects. BMC Med Genet 2004;5: 4.

16 Akar N, Hasipek M, Akar E, Ekim M, Yalçinkaya F, Cakar N: Serum amyloid A1 and tumor necrosis factor-alpha alleles in Turkish familial Mediterranean fever patients with and without amyloidosis. Amyloid 2003; 10:12-16.

17 Cazeneuve C, Ajrapetyan H, Papin S, RoudotThoraval F, Geneviève D, Mndjoyan E, Papazian M, Sarkisian A, Babloyan A, Boissier B, Duquesnoy P, Kouyoumdjian JC, GirodonBoulandet E, Grateau G, Sarkisian T, Amselem S: Identification of $M E F V$-independent modifying genetic factors for familial Mediterranean fever. Am J Hum Genet 2000;67: 1136-1143.

18 Yalçinkaya F, Ozen S, Ozçakar ZB, Aktay N, Cakar N, Düzova A, Kasapçopur O, Elhan AH, Doganay B, Ekim M, Kara N, Uncu N,
Bakkaloglu A: A new set of criteria for the diagnosis of familial Mediterranean fever in childhood. Rheumatology (Oxford) 2009;48: 395-398.

19 Mor A, Shinar Y, Zaks N, Langevitz P, Chetrit A, Shtrasburg S, Rabinovitz E, Livneh A: Evaluation of disease severity in familial Mediterranean fever. Semin Arthritis Rheum 2005;35: $57-64$.

20 Ozen S, Aktay N, Lainka E, Duzova A, Bakkaloglu A, Kallinich T: Disease severity in children and adolescents with familial Mediterranean fever: a comparative study to explore environmental effects on a monogenic disease. Ann Rheum Dis 2009;68:246-248.

21 Ajiro J, Narita I, Sato F, Saga D, Hasegawa H, Kuroda T, Nakano M, Gejyo F: SAA1 gene polymorphisms and the risk of AA amyloidosis in Japanese patients with rheumatoid arthritis. Mod Rheumatol 2006;16:294299.

22 Yilmaz E, Balci B, Kutlay S, Ozen S, Ertürk S, Oner A, Beşbaş N, Bakkaloğlu A: Analysis of the modifying effects of SAA1, SAA2 and TNF-alpha gene polymorphisms on development of amyloidosis in FMF patients. Turk J Pediatr 2003;45:198-202.

23 Mavragani CP, Yiannakouris N, Zintzaras E, Melistas L, Ritis K, Skopouli FN: Analysis of SAA1 gene polymorphisms in the Greek population: rheumatoid arthritis and FMF patients relative to normal controls. Homogeneous distribution and low incidence of AA amyloidosis. Amyloid 2007;14:271-275.

24 Chen M, Zhou H, Cheng N, Qian F, Ye RD; Serum amyloid A1 isoforms display different efficacy at Toll-like receptor 2 and formyl peptide receptor 2. Immunobiology 2014;219: 916-923.

25 Gouwy M, De Buck M, Pörtner N, Opdenakker G, Proost P, Struyf S, Van Damme J: Serum amyloid A chemoattracts immature dendritic cells and indirectly provokes monocyte chemotaxis by induction of cooperating CC and CXC chemokines. Eur J Immunol 2015; 45:101-112.

26 Yamada T, Wada A, Itoh Y, Itoh K: Serum amyloid A1 alleles and plasma concentrations of serum amyloid A. Amyloid 1999;6:199204.
27 Yamada T, Wada A: Slower clearance of human SAA1.5 in mice: implication for allele specific variation of SAA concentration in human. Amyloid 2003;10:147-150.

28 Lee HY, Kim MK, Park KS, Bae YH, Yun J, Park JI, Kwak JY, Bae YS: Serum amyloid A stimulates matrix-metalloproteinase- 9 upregulation via formyl peptide receptor like1-mediated signaling in human monocytic cells. Biochem Biophys Res Commun 2005; 330:989-998.

29 van der Hilst JC, Yamada T, Op den Camp HJ, van der Meer JW, Drenth JP, Simon A: Increased susceptibility of serum amyloid A 1.1 to degradation by MMP-1: potential explanation for higher risk of type AA amyloidosis. Rheumatology (Oxford) 2008;47:1651-1654.

30 Kishida D, Nakamura A, Yazaki M, TsuchiyaSuzuki A, Matsuda M, Ikeda S: Genotypephenotype correlation in Japanese patients with familial Mediterranean fever: differences in genotype and clinical features between Japanese and Mediterranean populations. Arthritis Res Ther 2014;16:439.

31 Gershoni-Baruch R, Brik R, Zacks N, Shinawi M, Lidar M, Livneh A: The contribution of genotypes at the $M E F V$ and $S A A 1$ loci to amyloidosis and disease severity in patients with familial Mediterranean fever. Arthritis Rheum 2003;48:1149-1155.

32 Merlini G, Bellotti V: Molecular mechanisms of amyloidosis. N Engl J Med 2003;349:583596.

33 Rocken C, Shakespeare A: Pathology, diagnosis and pathogenesis of AA amyloidosis. Virchows Archiv 2002;440:111-122.

34 Booth DR, Booth SE, Gillmore JD, Hawkins PN, Pepys MB: SAA1 alleles as risk factors in reactive systemic AA amyloidosis. Amyloid 1998;5:262-265.

35 Barakat MH, Karnik AM, Majeed HW, elSobki NI, Fenech FF: Familial Mediterranean fever (recurrent hereditary polyserositis) in Arabs - a study of 175 patients and review of the literature. Q J Med 1986;60:837-847.

36 Barsoum RS: End stage renal disease in the developing world. Artif Organs 2002;26:735736

37 Barsoum RS: End-stage renal disease in North Africa. Kidney Int Suppl 2003;S111-S114. 